\title{
Selective neuronal expression of the SoxE factor, Sox8, in direct pathway striatal projection neurons of the developing mouse brain
}

\author{
Paloma Merchan-Sala ${ }^{1}$, Diana Nardini ${ }^{3}$, Ronald R. Waclaw ${ }^{3}$, and Kenneth Campbell ${ }^{1,2,{ }^{*}}$ \\ ${ }^{1}$ Division of Developmental Biology, Cincinnati Children's Hospital Medical Center, University of \\ Cincinnati College of Medicine, 3333 Burnet Avenue, Cincinnati OH 45229, USA \\ ${ }^{2}$ Division of Neurosurgery, Cincinnati Children's Hospital Medical Center, University of Cincinnati \\ College of Medicine, 3333 Burnet Avenue, Cincinnati OH 45229, USA \\ ${ }^{3}$ Division of Experimental Hematology and Cancer Biology, Cincinnati Children's Hospital Medical \\ Center, University of Cincinnati College of Medicine, 3333 Burnet Avenue, Cincinnati OH 45229, \\ USA
}

\begin{abstract}
The striatum is the major component of the basal ganglia and is well known to play a key role in the control of motor function via balanced output from the indirect (iSPNs) and direct pathway striatal projection neurons (dSPNs). Little is known, however, about the molecular genetic mechanisms that control the formation of the iSPNs versus dSPNs. We show here that the SoxE family member, Sox 8, is co-expressed with dSPN marker, Isl1, in the developing striatum. Moreover, dSPNs, as marked by Isl1-cre fate map, express Sox 8 in the embryonic striatum and Sox 8 -EGFP BAC transgenic mice specifically reveal the direct pathway axons during development. These $\mathrm{EGFP}^{+}$axons are first observed to reach their midbrain target, the substantia nigra pars reticulata $(\mathrm{SNr})$, at $\mathrm{E} 14$ in the mouse with a robust connection observed already at birth. The selective expression of EGFP in dSPNs of Sox 8 -EGFPBAC mice is maintained at postnatal time points. Sox8 is known to be expressed in oligodendrocyte precursor cells (OPCs) together with other SoxE factors and we show here that the EGFP signal co-localizes with the OPC markers throughout the brain. Finally, we show that Sox 8 -EGFPBAC mice can be used to interrogate the altered dSPN development in IsI1 conditional mutants including aberrant axonal projections detected already at embryonic time points. Thus Sox8 represents an early and specific marker of embryonic dSPNs and the Sox 8 -EGFPBAC transgenic mice are an excellent tool to study the development of basal ganglia circuitry.
\end{abstract}

*Corresponding author: kenneth.campbell@cchmc.org.

ROLE OF AUTHORS

All authors contributed significantly to the research that led to preparation of this article. All authors had full access to all the data in the study and take responsibility for the integrity of the data and the accuracy of the data analysis. Study concept and design: PMS, RRW, KC. Acquisition of data: PMS, DN, RRW. Analysis and interpretation of data: PMS, RRW, KC. Drafting of the manuscript: PMS, RRW, KC. Critical revision of the manuscript for important intellectual content: PMS, RRW, KC. Obtained funding: KC. Administrative, technical, and material support: PMS, DN, RRW, KC. Study supervision: RRW, KC.

CONFLICT OF INTEREST

None of the authors have a known or potential conflict of interest including any financial, personal or other relationships with other people or organizations within three years of beginning the submitted work that could inappropriately influence, or be perceived to influence, the work presented in this article. 


\section{Keywords}

Basal ganglia; Development; Neural circuit; Striatonigral pathway

Basal ganglia circuits play a central role in the processing of motor, emotional and intellectual brain functions (Macpherson et al., 2014; Obeso et al., 2014). The principal structure of the basal ganglia, the striatum (a.k.a. caudate-putamen), contributes to this processing through the two major GABAergic output pathways, which comprise the indirect pathway striatal projection neurons (iSPNs) and direct SPNs (dSPNs) (Gerfen and Surmeier, 2011). Balanced activity in these two pathways is thought to be essential for normal motor control (Albin et al., 1989; Albin, 1995; Albin and Tagle, 1995; Gerfen and Surmeier, 2011), Moreover, alterations in the development and/or function of basal ganglia circuits are believed to underlie aspects of childhood neuropsychatric disorders such as obsessive compulsive disorder (OCD) and attention deficit hyperactivity disorder (ADHD) (Leisman and Melillo, 2013). Despite this, little is known about the development of these SPN pathways at embryonic or postnatal stages.

SPNs are known to arise from the lateral ganglionic eminence (LGE) located in the ventral telencephalon, largely during the second half of embryogenesis (Deacon et al., 1994; Olsson et al., 1995, 1998; Wichterle et al, 2001). A number of developmental control genes including Gsx 1/2, Ascl1 and Dlx genes are expressed by LGE progenitors and have been shown to be required for the normal development of LGE-derived neuronal subtypes, including the SPNs (Anderson et al., 1997; Casarosa et al., 1999; Corbin et al., 2000; Toresson et al., 2000; Toresson and Campbell, 2001; Yun et al., 2001; Yun et al., 2002, 2003; Long et al., 2009; Waclaw et al., 2009; Wang et al., 2009, 2011, 2013; Pei et al., 2011). A number of transcription factors mark differentiating SPNs in both the indirect and direct pathways including Nolz1/Zfp503, Ctip2 and Foxp1 (Chang et al., 2004; Tamura et al., 2004; Arlotta et al., 2008; Ko et al., 2013). Moreover, Ctip2 and Foxp1 have been shown to be required for the normal differentiation of SPNs (Arlotta et al., 2008; Bacon et al., 2015). The zinc finger transcription factor Sp9 is expressed by most subventricular zone cells of the LGE, however, it's expression resolves to the iSPNs at postnatal stages and is required for the proliferation and postnatal survival of this SPN subtype (Zhang et al., 2016). Conversely, the early B cell factor $E b f 1$, is known to be required for the normal development and connectivity of dSPNs, particularly in the matrix compartment (Garel et al., 1999; Lobo et al., 2006; Lobo et al., 2008). More recently, the LIM homeobox gene Isl, has been shown to be selectively expressed in dSPN progenitors and is required for the survival of newborn dSPNs, already at embryonic stages (Ehrman et al., 2013; Lu et al., 2014). Not all dSPNs require Isl1 for their survival/differentiation as a portion remain in the Is 11 mutants marked by Ebf1 expression (Ehrman et al., 2013).

In this study, we have examined the embryonic and postnatal striatal neuron expression of the SoxE factor, Sox8, which has previously been associated with oligodendrocyte precursor cells (OPCs) (Sock et al., 2001; Stolt et al., 2004, 2005). In addition to OPCs, we show here that Sox 8 specifically marks dSPNs, particularly in the dorsal striatum. Additionally, we have characterized Sor8-EGFP mice and show that the EGFP faithfully represents Sox8 in 
dSPNs while filling the entire cytoplasm (including processes), making the mice a valuable tool to study development of the direct pathway during development.

\section{MATERIALS AND METHODS}

\section{Animals}

Drd1-EGFP(RRID: MMRRC_000297-MU), Drd2-EGFP(RRID: MMRRC_000230-UNC) and Sox8-EGFP(RRID: MMRRC_031855-UCD) BAC transgenic mice were obtained from the Mutant Mouse Regional Resource Center (MMRRC), a NCRR-NIH funded strain repository. These mouse lines were donated to the MMRRC by the NINDS funded GENSAT BAC transgenic project (The Gene Expression Nervous System Atlas Project, NINDS Contracts N01NS02331 \& HHSN271200723701C to The Rockefeller University (New York, NY). Drd1-tdTomato and Rosa-tdTomato (Ai14) mice were obtained from Jackson laboratories (RRID:IMSR_JAX:016204 and RRID:IMSR_JAX:007914). All EGFP expressing reporter mice were genotyped as described (Ehrman et al., 2013) while tdTomato expressing mice were genotyped as described in (Qin et al., 2016). Two cre mouse lines were used: $I s 1^{c r e /+}$ mice (Srinivas et al., 2001), provided by T. Jessell (Columbia University, New York, NY) and Dlx1-cre BAC transgenic mice (RRID: MMRRC_036076-UCD) obtained from the MMRRC donated by the GENSAT BAC transgenic project, as above. Both were genotyped using cre primers as described (Qin et al., 2016). The $I s I 1^{f \mid x / f l x}$ mice (Mu et al., 2008) were obtained from X. Mu (University of Buffalo, Buffalo, NY) and W. H. Klein (MD Anderson Cancer Center, Houston, TX) and genotyped as described (Mu et al., 2008). Gs $x 2^{R A /+}$ mice were crossed and maintained as described (Waclaw et al., 2009). All animal care was approved by the Institutional Animal Care and Use Committee (IACUC) at the Cincinnati Children's Hospital Medical Center (CCHMC).

\section{Tissue preparation}

Embryos were staged by designating the morning of vaginal plug detection as E0.5. The date of birth was considered as P0. Embryos and postnatal brains were fixed overnight in $4 \%$ paraformaldehyde at $4^{\circ} \mathrm{C}$ and thoroughly rinsed in PBS. Before sectioning, embryos were cryoprotected in $30 \%$ sucrose before cryostat sectioning at $12 \mu \mathrm{M}$. Postnatal brains were cryoprotected in $15 \%$ sucrose and sectioned at $35 \mu \mathrm{M}$ on a freezing sliding microtome.

\section{Immunohistochemistry}

Standard immunostaining protocol was performed as previously described (Waclaw et al., 2009). Briefly, cryosections were rinsed in KPBS $0.1 \%$ Triton followed by $1 \mathrm{~h}$ blocking with specific serums (NDS, NGS from Jackson Immunoresearch laboratories) and incubated with primary antibody over night at room temperature (see Table 1 for details). Sections were rinsed in KPBS with $0.1 \%$ triton and incubated for 2-3h at room temperature with fluorescent secondary antibody (1:300 dilution, Jackson Immunoresearch laboratories) (Table 1) then rinsed and cover slipped using Fluoromount-G (Southern Biotech). For floating sections $0.3 \%$ Triton was used instead of $0.1 \%$. 


\section{Antibody characterization}

The Isl1 antibody was obtained from R and D systems (cat\# AF1837, RRID:AB_2126324). It has been previously used to mark a variety of neuronal populations in the mouse brain. The expression pattern observed in this work is consistent with the previously published reports (Toresson et al., 2000; Toresson and Campbell, 2001; Waclaw et al, 2009)

The Sox8 antibody was provided by Dr. Michael Wegner (University of ErlangenNuremberg; Bavaria; Germany RRID: AB_2571872). The antibody was generated in guinea pig against a purified bacterially expressed protein consisting of amino acids 2-60 of mouse Sox8 fused to glutathione S-transferase (Stolt et al., 2005).

The tdTomato immunostaining was performed using a rabbit polyclonal DsRed antibody from Clontech Laboratories, Inc. (cat\# 632496, RRID: AB_10015246). The antibody is raised against DsRed-Express, a variant of Discosoma sp. red fluorescent protein. This antibody recognizes DsRed-Express, DsRed-Express2, DsRed-Monomer, mCherry, DsRed2, E2-Crimson, tdTomato, mStrawberry, and mBanana, and both $\mathrm{N}$ - and C-terminal fusion proteins containing these fluorescent proteins in mammalian cell lysates (manufacturer's datasheet). Specificity was confirmed by immunostaining of tdTomato ${ }^{-}$brains.

The EGFP antibody was purchased from Aves Labs (cat\# GFP-1020, RRID:AB_10000240). IgY fractions obtained from immunized chickens were affinitypurified using an agarose matrix to which the recombinant protein was attached. The antiserum was analyzed by western blot analysis and immunohistochemistry using transgenic mice expressing the GFP gene product (manufacturer's datasheet). No staining was observed in sections of $\mathrm{GFP}^{-}$brains from litter mates.

Anti-FoxP1 was purchased from Abcam and was used to identify the striatal projection neurons (cat\# ab57216, RRID:AB_941648). Our immunostaining for FoxP1 shows a distribution pattern in the mouse brain consistent with published reports (Wang et al., 2011)

The rabbit Ebf1 antibody was purchased from Millipore (cat\# AB10523, RRID: AB_2636856). According to the manufacturer's datasheet it recognizes Ebf1 but not Ebf2 or Ebf3, from human and mouse origin, in dot blot and in Western blot analysis of COS7 transfected cells. Our expression pattern correlates with previous reports (Hua et al., 2014).

The Nkx2.1 antibody was obtained from Seven Hills Bioreagents (cat\# WRAB-1231, RRID: AB_451727). This polyclonal antibody is raised in rabbit and was used to define striatal interneurons as previously described in Marin et al., (2000). Our staining is consistent with previous published reports (Marin et al., 2000; Xu et al., 2008).

The Sox9 antibody is a rabbit polyclonal from Santa Cruz Biotechnology which was raised against amino acids 407-496 mapping near the C-terminus of Sox-9 of human origin. A single specific $65 \mathrm{kDa}$ band was observed by Western blot on mouse Sox 9 transfected cells (cat\# sc-20095, RRID:AB_661282). 
The goat polyclonal Sox10 antibody was obtained from Santa Cruz Biotechnology (cat\# sc-17342, RRID: AB_2195374). This antibody recognizes a single band of about $60 \mathrm{kDa}$ on mouse brain lysates in Western blot analysis (manufacturer's datasheet).

The O1ig2 antibody was purchased from Millipore (cat\# AB9610, RRID:AB_570666). This polyclonal antibody was raised in rabbit and recognizes a 32-kDa band by western blotting on mouse brain lysate (manufacturer's information) and has been previously described to reveal distribution of oligodendrocytes and their precursor cells (OPCs) in the mouse brain (see e.g. (Ehrman et al., 2014).

PDGFRa antibody was obtained from Santa Cruz Biotechnology (cat\# sc-338, RRID: AB_631064). This is an affinity purified rabbit polyclonal antibody raised against a peptide mapping to the C-terminal region of human PDGFRa. In Western blot, it recognizes a single $170 \mathrm{kDa}$ band on NIH/3T3 whole cell lysates (manufacturer's datasheet). This antibody has previously been used to identify OPCs in the mouse telencephalon (see e.g. (Ehrman et al., 2014)

The TH antibody was purchased from Aves Labs (cat\# TYH, RRID:AB_10013440). Chickens were immunized with two synthetic peptide/keyhole limpet hemocyanin (KLH) conjugates. These synthetic peptides corresponded to different regions of the Tyrosine Hydroxylase gene product (EC 1.14.16.2). These peptide sequences are shared between the mouse (P24529) and human (P07101) gene products (Erickson et al., 2012)

Substance P antibody was obtained from Millipore (cat\# MAB356, RRID:AB_94639) has been previously used to identify the direct pathway medium-sized spiny neuron collaterals (Gonzales et al., 2013). The specificity of the substance P antibody has been demonstrated by showing the equal displacement of labeled Substance P by five-, six-, and eight-amino acid COOH-terminal fragments of Substance P, as well as full-length Substance P, and by the specific binding of these antibodies with cell bodies and terminals located in welldefined Substance P-containing nuclei in the central nervous system. Our staining results were consistent with that of Gonzales et al. (2013).

\section{In situ hybridization}

The in situ hybridization procedure was performed as previously described (Toresson et al., 1999). Digoxigenin-labeled antisense probes against Sox8 (Clone ID: 6306276: Dharmacon) were used on $12 \mu \mathrm{m}$ sections of E11.5, E13.5 and E18.5 embryos.

\section{Imaging and cell counting}

Images were captured using a Nikon AIRSi or C2 Inverted Confocal Microscope or an Olympus BX-51 microscope equipped with epiflourescence and processed when needed for brightness and contrast using Adobe Photoshop CS6 (Adobe Systems Inc., San Jose, CA, USA). Cell counts were done using NIS Elements AR 4.5 software (Nikon Instruments Inc.) on three consecutive 400x confocal pictures from 2-3 animals each. Between 1001 and 1325 $\mathrm{DAPI}^{+}$cells were analyzed for each staining condition. Images were taken from the central portion of the dorsal striatum at E18.5. 


\section{RESULTS}

\section{Sox8 is present in dSPN progenitors}

The HMG box transcription factor, Sox 8 is known to be expressed in OPCs and to play a compensatory role in oligodendrogenesis in the absence of either Sox 9 or Sox 10 (Sock et al., 2001; Stolt et al., 2004; Stolt et al., 2005), however, no detailed report on the expression of this factor in neuronal populations exists. A previous study by Sock et al. (2001), in which lac $Z$ was used to replace the $S o x 8$ locus, showed extensive beta-galactosidase staining in the developing striatum. Hence, we set out to carefully analyze Sox8 expression within the ventral telencephalon and in particular in developing striatal projection neurons (SPNs) of the direct (dSPN) and indirect (iSPN) pathways.

Isl1 (a LIM homeobox factor) has recently been shown to be expressed in progenitors of the direct pathway and is required for the survival/differentiation of a subpopulation of dSPNs (Ehrman et al., 2013; Lu et al., 2014). Double immunostaining for Isl1 and Sox8 shows significant co-expression of these factors within the subventricular zone (SVZ) of the LGE as well as in the forming striatum, particularly in the dorsal and medial region at E15.5 (Fig. 1C). While co-expression in the medial striatum was widespread, Sox 8 exhibited unique expression within the ventricular zone (VZ) and was absent from the superficial SVZ appearing again deep in the $\mathrm{SVZ}$ and maintaining a high to low gradient of expression in SPNs across the medial-lateral aspect of the striatum (Fig. 1B,C). Isl1 is expressed in the superficial SVZ and continues with a less pronounced medial-lateral gradient in the striatum (Fig. 1A,C). The early B cell factor, Ebf1 is also known to be essential for correct formation of the dSPNs (Lobo et al., 2006; Lobo et al., 2008). Ebf1 is expressed in deep portions of the SVZ as well as in a rather uniform manner throughout the mediolateral extent of the developing striatum at E18.5 (Fig. 1D). At E18.5, Sox8 shows a very similar pattern of expression with a pronounced high-medial to low-lateral gradient in the striatum (Fig. $1 \mathrm{E}$, F). Quantification of double labeling with the dSPN markers in the central portion of the dorsal striatum at E18.5 showed that 59\% of Isl1 ${ }^{+}$cells co-expressed Sox8 (163 cells Isl1 ${ }^{+}$/ Sox $8^{+}$out of 278 total Is $11^{+}$cells), while $56 \%$ of Ebf $1^{+}$cells co-labeled with Sox 8 ( 170 cells Ebf $1^{+} / \mathrm{Sox} 8^{+}$out of 305 total Ebf $1^{+}$cells).

Using the $I s 1^{\text {cre }}$ mice (Srinivas et al., 2001), we fate mapped the dSPNs (Ehrman et al., 2013; Lu et al., 2014) and co-labeled with Sox8 at E15.5 and E18.5 (Fig. 1G-K). The vast majority of tdTomato expressing Isl1 fate mapped cells (i.e. dSPNs) co-express Sox8 at both stages (Fig. 1H,I,K). Indeed, at E15.5, the vast majority of tdTomato-positive dSPNs in the dorsal striatum were observed to express Sox8 (Fig 1I). Thus Sox8 exhibits a complex expression pattern within the LGE/striatum that partially overlaps with that of Isl1 and Ebf1, particularly in the developing dSPNs (Fig. 1L). Hence, these results suggest that Sox8 represents a new marker of dSPNs in addition to the previously established Isl1 (Ehrman et al., 2013; Lu et al., 2014) and Ebf1 (Lobo et al., 2006; Lobo et al., 2008).

We also performed a comparative analysis of Sox 8 gene and protein expression over 3 stages; E11.5 prior to SPN differentiation, E13.5 an early stage of striatal neurogenesis and E18.5 near the completion of striatogenesis (Fig. 2). Interestingly, at E11.5, Sox 8 gene and protein expression is largely confined to the $\mathrm{VZ}$ of the ventral telencephalon (Fig. 2A,C). By 
E13.5, Sox 8 gene and protein expression in the $\mathrm{VZ}$ is expanded dorsally to the pallium with a gradient of expression from ventral to dorsal (Fig. 2E,G). At this stage, expression in the LGE SVZ and developing striatum is evident (Fig. 2E,G). This pattern remains until E18.5, however, the medial-lateral gradient in the maturing striatum, as described above, becomes evident (Fig. 2I,K). Additionally, scattered $50 x 8$ gene and protein expressing cells were observed in adjacent cortical regions similar in their distribution to migrating OPCs (Fig. 2I,K), which have been shown to express Sox8 at multiple levels of the neuraxis (Sock et al., 2001; Stolt et al., 2004, 2005). The homeobox gene Gsx 2 is known to be required for correct dorsal-ventral patterning of the LGE and subsequent formation of the striatum (Corbin et al., 2000; Toresson et al., 2000; Toresson and Campbell, 2001; Yun et al., 2001, 2003; Waclaw et al., 2009). We examined Sox 8 gene and protein expression in the $G s x 2^{R A / R A}$ null mutant (Waclaw et al., 2009) and found an initial ventral shift of its dorsal limit (Fig. 2B,D), similar to that observed for other ventral telencephalic genes (e.g. Ascl1, Dlx factors) in these mutants (Corbin et al., 2000; Toresson et al., 2000; Yun et al., 2001). No noticeable change in the VZ expression was observed at later stages in the Gsx 2 mutants, however, expression in the forming striatum was notably reduced (Fig. 2F,H, J, L), as seen for other striatal markers such as, Isl1, in these mutants (Toresson et al., 2000; Toresson and Campbell, 2001; Waclaw et al., 2009; Wang et al., 2011). Thus, Sox8 initially behaves similar to ventral telencephalic genes within the $\mathrm{VZ}$ at early stages corresponding with the observed patterning defect in striatal development but at later stages the VZ expression appears to be independent of Gsx2 gene function.

\section{Characterization of Sox8-EGFP BAC mice}

A number of BAC transgenic lines have previously been used to fluorescently mark either the iSPNs or dSPNs together with their axonal projections (Lobo et al., 2006; Wang et al., 2006; Lobo et al., 2008; Shuen et al., 2008; Ehrman et al., 2013) Many of these BAC transgenes, however, contain genes expressed highly in mature SPNs and thus may not provide robust labeling of the developing SPNs and their axonal trajectories. Given our findings that Sox8 appears to mark the dSPNs at embryonic stages, we examined EGFP expression in Sox 8-EGFPBAC transgenic mice generated by the GENSAT project (Gong et al., 2003) to determine if these mice provide a reliable tool to visualize the development of the direct pathway already at embryonic time points. Although we were able to detect EGFP expression as early as E12.5 (see Fig. 4) we initially focused on E16.5 and E18.5 when the striatal complex is well delineated. First, we compared the expression of EGFP and Sox 8 at E16.5 and found that, with the exception of the VZ expression of Sox8 (Fig. 3A), EGFP immunostaining co-labels extensively with Sox8 in the SVZ and developing striatum (particularly the dorsomedial striatal region) (Fig. 3A-C). In addition to the mediolateral gradient of Sox8 (see Fig. 1), both Sox8 and EGFP also show a high-dorsal to low-ventral gradient within the striatal complex (Fig. 3A-C).

The SPNs comprise around 90-95\% of the cells in the mature striatum (Kemp and Powell, 1971) with the remaining 5-10\% representing different subtypes of interneurons (Kawaguchi, 1993). The forkhead transcription factor Foxp1 is known to mark the vast majority of SPNs belonging to both the direct and indirect pathway (Arlotta et al., 2008). In the Sox8-EGFP striatum at E18.5 staining for Foxp1 showed that the vast majority of the 
$\mathrm{EGFP}^{+}$cells were FoxP1 ${ }^{+}$(Fig. 3D-F). We next co-stained the Sox 8-EGFP striatum with dSPN markers and found that $76 \%$ of Isl $1^{+}$cells co-express EGFP (Fig. 3G-I, 212 Isl1 $^{+} /$ $\mathrm{EGFP}^{+}$cells out of a total of 278 Isl1 ${ }^{+}$cells) and $78 \%$ of the Ebf $1^{+}$cells co-labeled EGFP (Fig. 3J-L, $239 \mathrm{Ebf1}^{+} / \mathrm{EGFP}^{+}$cells out of a total of $305 \mathrm{Ebf1} 1^{+}$cells). Striatal interneurons are known to migrate tangentially from the medial ganglionic eminence (MGE) and settle in the forming striatum (Marin et al., 2000). These neurons express the transcription factor Nkx2.1 (Marin et al., 2000). Double immunostaining for Nkx2.1 and EGFP showed that there is no detectable colocalization between the two markers (Fig. 3M-O), indicating that Sox8-expressing striatal cells are not interneurons. Taken together, Sox8 appears to mark dSPNs and their progenitors from early stages and the Sox 8 -EGFPBAC mice represent a useful tool for studying this neuronal population at embryonic time points.

The defining feature of dSPNs is their axonal projections to the substantia nigra including the pars reticulata ( $\mathrm{SNr}$ ) (Gerfen, 2004). Thus we decided to carefully analyze the origin and destination of the $\mathrm{EGFP}^{+}$axonal projections in Sox 8-EGFPembryos in sagittal sections at different embryonic stages. We first observed $\mathrm{EGFP}^{+}$axons emanating from the developing dorsal striatum at E12.5, however, they only extend to the diencephalon at this stage (Fig. 4A). By E14.5, some of the EGFP ${ }^{+}$axons can be observed reaching all the way to the $\mathrm{SNr}$ (Fig. 4B). At E16.5, the $\mathrm{EGFP}^{+}$axons projecting to the substantia nigra are numerous and begin arborizing within the $\mathrm{SNr}$ (Fig 4C,D). The neuropeptide substance $\mathrm{P}$ is an established marker of the direct pathway SPNs (Gerfen, 2004). We were able to identify EGFP/ Substance $\mathrm{P}$ double positive processes in the $\mathrm{SNr}$ as early as E16.5 (Fig 4D), further supporting the notion that Sox8-EGFP neurons are dSPNs. In agreement with the fact that most SPNs are generated by birth, the direct pathway appears to be largely complete by E18.5 (Fig. 4F). The reciprocal nature of the striatonigral and nigrostriatal pathways has been well documented (reviewed in Gerfen, 2004) thus we examined the formation of these intimately associated pathways in the $S 0 x 8-E G F P$ mice. Indeed, a clear $\mathrm{SNc} / \mathrm{SNr}$ structure is evident at E16.5 and E18.5 (Fig. 4E,I). Moreover, the close association of descending dSPN axons and ascending dopamine fibers (marked by tyrosine hydroxlase) can be seen before birth within the internal capsule (Fig. 4H). This is also true at striatal levels where dopamine terminals show close association with the $\mathrm{EGFP}^{+}$(i.e. dSPN) cell bodies (Fig. 4G). Thus the Sox 8-EGFP mice represent a very useful tool to study the formation of basal ganglia circuitry especially as it relates to the direct pathway.

A widely exploited approach to identify dSPNs and iSPNs in the postnatal/adult brain has been to utilize the Drd1-EGFP and Drd2-EGFP BAC transgenic mice (Lobo et al., 2006, 2008; Wang et al., 2006; Shuen et al., 2008; Ehrman et al., 2013). At perinatal time points, however, the Drd1-EGFP transgene is only expressed in subsets of SPNs, apparently in the patch (striosomal) compartment (Fig. 5A). Despite the low number of SPNs expressing Drd1-EGFP at birth, most of these neurons also co-expressed Sox8 protein (Fig. 5B). In contrast, the Drd2-EGFP BAC transgene marks large numbers of SPNs throughout the newborn striatal complex (Fig. 5C) and none of these EGFP ${ }^{+}$neurons co-expressed Sox 8 (Fig. 5D). To determine how specific the Sox8-EGFPexpression was to dSPNs in the postnatal brain, we crossed the mice with Drd1-tdTomato mice (Shuen et al., 2008) and analyzed them at P7, when the Drd1 BAC transgene is expressed throughout the striatal complex (Fig. 5F). Again, at this time point, the EGFP showed a higher expression level 
within the dorsal striatum and only weak expression in the ventral striatum, including the nucleus accumbens (Fig. 5E). In line with the embryonic studies described above, we observed a high degree of overlap between the Sox 8 driven EGFP and $\operatorname{Drd} 1$ driven tdTomato within the dorsal striatum as well as along the direct pathway trajectories (Fig. 5G-K), supporting the notion that Sox 8 is an early marker of dSPNs and that Sox 8 -EGFPBAC mice represent an excellent tool to follow the formation of the direct pathway from embryonic to postnatal stages.

As mentioned above, Sox8 (and Sox 8-EGFP) marks a population of cells that are scattered throughout the brain parenchyma including the telencephalon, diencephalon and midbrain resembling migrating OPCs (Figs. 2I,K and 4F). To determine if these Sox 8 (and Sox 8 $E G F P$ ) cells were, in fact, OPCs, we co-stained with glial markers. These scattered EGFP $^{+}$ cells exhibited a morphology resembling OPCs and expressed Sox8 in cortex, hypothalamus and dorsal thalamus (Fig. 6A,B,C). Moreover, these cells were double positive for Sox 9 (Fig. 6D,E), Sox 10 (Fig. 6F,G), Olig2 (Fig. 6H,I) and PDGFRa (Fig. 6J,K) in the cortical areas examined. In fact, cortical $\mathrm{EGFP}^{+}$cells were approximately $90 \%$ positive for Olig2 and PDGFRa. Moreover, similar cells were observed within the parenchyma of the hypothalamus (Fig. 6B), diencephalon (Fig. 6C) and the white matter tracts as well as midbrain/hindbrain regions (data not shown). Thus, Sox 8 -EGFPBAC mice faithfully label OPCs throughout the brain in addition to the specific labeling of dSPNs within the striatum.

\section{Sox8-EGFP BAC transgene on the Is/1 conditional mutant background}

Our previous work suggested that Isl1 is required cell autonomously for survival of a significant subpopulation of dSPNs as well as non-cell autonomously for the normal formation of the striatonigral axonal trajectory via the internal capsule (Ehrman et al., 2013). However, we were only able to examine these axonal trajectories at adult time points as we were unable to specifically and robustly label the forming direct pathway in embryonic and early postnatal IsII conditional mutants (cKOs).

In this study, we have utilized the Sox8-EGFPallele to examine the formation of the direct pathway in Dlx1-cre; Isl fll/fl animals at birth (i.e. P0). In contrast to the control animals (Fig. 7A), a clear reduction in $\mathrm{EGFP}^{+}$striatal cells and dSPN axons was apparent in the IsI1 cKO brain (Fig. 7B). In addition to the reduced number of $\mathrm{EGFP}^{+}$dSPNs in the $I s I 1 \mathrm{cKO}$ striatum, we observed considerable alterations in the $\mathrm{EGFP}^{+}$axonal trajectories along the direct pathway of the conditional mutants (Fig. 7B). We previously showed that deletion of Isl1 using DIx5/6-CIE mice resulted in a major loss of reticular thalamus neurons (Ehrman et al., 2013). Using the Dlx1-cre BAC mice, Isl1 is also severely reduced in the reticular thalamus of the $\mathrm{cKO}$ (Fig. 7D). Notably, at the level of the reticular thalamus in these mutants, many $\mathrm{EGFP}^{+}$axons were observed to invade the dorsal thalamus in the cKOs, but not the controls (compare Fig. 7D with C). Furthermore, Sox8 protein expression was reduced in the $I s 11 \mathrm{cKO}$ striatum (Fig. 7F), as compared to the control (Fig. 7E). This reduction in Sox8 (and EGFP) expression likely reflects the significant cell death phenotype observed in dSPNs of the IsI1 cKOs (Ehrman et al., 2013; Lu et al., 2014). Therefore the Sox 8 -EGFPBAC mice represent an excellent tool to study perturbations to the direct pathway in defined genetic lesions. 


\section{DISCUSSION}

The SoxE factors, including Sox8, Sox9 and Sox10 are well known regulators of glial development and in particular OPCs and oligodendrogenesis (Sock et al., 2001; Stolt et al., 2004, 2005). In this study we have characterized novel neuronal expression of the SoxE factor, Sox8, specifically within dSPNs of the embryonic and postnatal mouse striatum. Additionally, we have characterized EGFP expression in Sox8-EGFPBAC transgenic mice and demonstrated that the EGFP accurately reflects Sox8 expression in dSPNs and their axonal projections as well as in OPCs throughout the perinatal brain. Thus Sox8 represents a novel marker of dSPNs from embryonic to postnatal time points and the Sox8-EGFPBAC mice provide a useful tool to study assembly of basal ganglia circuitry.

Although Sox8 is expressed in OPCs, no significant glial phenotypes have been reported in the $\operatorname{Sox} 8$ mutants (Sock et al., 2001). Sox9 has been shown to be required for OPC specification while Sox 10 plays important roles in oligodendrocyte differentiation (Stolt et al., 2002, 2003). While Sox 8 mutants have only been shown to exhibit a transient delay in terminal differentiation and myelination within the mutant spinal cord (Stolt et al., 2004), removal of Sox 8 from either the Sox 9 or Sox 10 mutant backgrounds exacerbates both of the phenotypes (Stolt et al., 2004; Stolt et al., 2005). Despite this, it appears that Sox8 is not completely redundant with these SoxE factors, as the replacement of the Sox 10 locus with Sox 8 , does not fully rescue the Sox 10 mutant phenotype (Stolt et al., 2005; Kellerer et al., 2006). Interestingly, this appears to be the first description of a SoxE factor in a defined neuronal subtype lineage. Using Isl1-cre mice (Srinivas et al., 2001) to mark the direct pathway (Ehrman et al., 2013; Lu et al., 2014) we demonstrate here that Sox8 is expressed by newborn SPNs and specifically those that belong to the direct pathway (i.e. dSPNs).

Despite the reduction in Sox 8 expressing cells within the $I s 11 \mathrm{cKO}$ striatum, it appears that at least a portion of the remaining dSPNs in this mutant do express Sox 8 and that the loss of Sox8-expressing cells is likely due to the considerable neuronal death occurring within the mutant dSPNs (Ehrman et al., 2013; Lu et al., 2014). This suggests that Sox 8 is not directly regulated by Isl1 and may thus control a parallel pathway in dSPN differentiation. This is in line with the maintained expression of Ebf1 in the remaining dSPNs of the Is $11 \mathrm{cKO}$ mutants (Ehrman et al., 2013; Lu et al., 2014). Therefore, it will be interesting to determine the relationship between Sox 8 and Ebf1, which represents the other major regulator of dSPN development (Lobo et al., 2006; Lobo et al., 2008). Ebf1 has been shown to be expressed in, and required for development of the matrix compartment (Garel et al., 1999). Moreover, it regulates dSPN development rather specifically within this compartment of the striatum (Lobo et al., 2008). However, it does not appear that Sox8 is differentially expressed in the matrix versus the patch (striosome) compartment (data not shown) and thus may be regulated by other factors within the developing striatal patches.

We were surprised to observe the ventral restriction of Sox 8 gene and protein expression in the VZ of the E11.5 telencephalon given its broad dorsoventral extent within the VZ at later stages. At this early time point, $\operatorname{Sox} 8$ is subject to dorsoventral patterning constraints typical of most other ventral telencephalon restricted genes. The homeobox gene Gsx 2 represents an important regulator of ventral patterning in the telencephalon and is required for normal 
ventral telencephalic gene expression (Corbin et al., 2000; Toresson et al., 2000; Yun et al., 2001; Waclaw et al., 2009; Wang et al., 2013). In GsX2 mutants, we found that the dorsal limit of Sox 8 expression is shifted ventral as is the case with other ventral telencephalic regualtors such as Ascl1 and Dlx factors. By E13.5, however, the VZ expression of Sox8 appears to be independent of $G s \times 2$ function showing a similar dorsal extent to that in control embryos. This suggests a complex regulation of $50 x 8$ gene expression within the telencephalic VZ and possibly different roles at early versus late stages, perhaps in neurogenesis versus gliogenesis.

Sox8-EGFPBAC mice have been generated by the GENSAT project (Gong et al., 2003). Characterizing these mice showed that they mark dSPNs from early stages of striatogenesis as well as considerable numbers of OPCs throughout the brain. Interestingly, the VZ expression of Sox 8 was not observed in the Sox 8 -EGFPBAC mice at any stage analyzed. Thus the enhancer elements driving this expression are not represented in the BAC used to create these mice. The majority of EGFP ${ }^{+}$neurons in the striatum expressed the dSPN markers, Isl1 (Ehrman et al., 2013; Lu et al., 2014) and Ebf1 (Lobo et al., 2006; Lobo et al., 2008) but not the striatal interneuron marker Nkx2.1 (Marin et al., 2000). At postnatal stages, the Sox8-EGFP transgene showed considerable overlap with the Drd1-tdTomato transgene (Shuen et al., 2008), at least in dorsal striatal regions where the EGFP signal was most abundant. Similarly, when the $\mathrm{EGFP}^{+}$cells with OPC morphologies were investigated, the overwhelming majority co-expressed all of the typical OPC markers. Thus Sox 8 -EGFP BAC mice represent a very useful tool to mark the dSPNs from embryonic to postnatal stages as well as large populations of OPCs. Presumably the developmental history of these $\mathrm{EGFP}^{+}$neural subtypes is quite distinct given the restricted generation and migration of dSPNs and the widespread distribution of labeled OPCs. These reporter mice, however, may be useful tools to dissect the lineage relationship between dSPNs and LGE-derived OPCs.

In addition to the cell body labeling, the EGFP expressed in the Sox 8 -EGFP mice also fills the neuronal processes of labeled cells and thus marks the axons and terminals. This characteristic also helped to define the $\mathrm{EGFP}^{+}$cells as dSPNs due to the axonal projections through the internal capsule towards, and into, the SNr. As mentioned above, there is considerable overlap in the EGFP and tdTomato signals in axons of the direct pathway in Sox8-EGFP; Drd1-tdTomato double transgenic mice at postnatal stages. Unlike the Drd2$E G F P \mathrm{BAC}$ transgene which appears to be expressed in large numbers of iSPNs already at embryonic time points (Morello et al., 2015), the Drd1-EGFPBAC transgene is only found in a small subpopulation of dSPNs. Therefore, the Sox 8 -EGFPBAC transgene allows us to mark the direct pathway already at embryonic stages. Indeed, we observe EGFP expression in neurons within the E12.5 LGE mantle (i.e. forming striatum) of the Sox8-EGFPembryos. At this time point, the EGFP ${ }^{+}$axons only reach as far as the diencephalon, however, 2 days later at E14.5 the first EGFP ${ }^{+}$axons can be seen to invade the ventral midbrain in the vicinity of the SNr. A previous study, using retrograde tracing, indicated that the striatonigral axons first reach the midbrain around E17 in the rat (Fishell and van der Kooy, 1987). This would correlate to about E14.5 in the mouse according to the Translating Time website (http://www.translatingtime.net), as the mouse is approximately 2 days shorter gestation (Workman et al., 2013). Thus our findings in the Sox8-EGFPBAC mice support the timing of dSPN innervation of the SNr shown by Fishell and van der Kooy (1987) and indicate that 
these mice represent a excellent tool to study the formation of this crucial basal ganglia circuit component.

Formation of the direct pathway depends on two major transcription factors Isl1 and Ebf1 (Garel et al., 1999; Lobo et al., 2006, 2008; Ehrman et al., 2013; Lu et al., 2014). Isl1 plays a cell autonomous role in regulating survival of newborn dSPNs and a non-cell autonomous role in regulating the normal formation of the internal capsule in which the direct pathway axons travel (Ehrman et al., 2013; Lu et al., 2014). Inactivation of Isl1 in the embryonic ventral thalamus results in the loss of the reticular thalamus neurons (Ehrman et al., 2013), which correlates well with the observed defects in the internal capsule and direct pathway trajectory at postnatal times. We bred the Sox8-EGFP allele onto the Dlx1-cre; IsI1 cKO background to examine the direct pathway at perinatal time points and found that numerous $\mathrm{EGFP}^{+}$axons aberrantly invade the dorsal thalamus at the level of the reticular thalamus in the IsI1 cKOs at birth. Repulsive Plexin D1-Sema 3e signaling has been proposed to regulate normal internal capsule and direct pathway formation (Chauvet et al., 2007; Ehrman et al., 2013). In fact, Sema 3e is expressed by the ventral thalamus (precursor to the reticular thalamus) and Plexin D1 uniquely defines the dSPNs (Chauvet et al., 2007; Ehrman et al., 2013; Lu et al., 2014). Chauvet et al. (2007) showed that Sema 3e mutants exhibit aberrant innervation of Plexin D1 axons originating from the internal capsule within the dorsal thalamus. Moreover, Sema 3e mutants show disruptions in direct pathway axonal trajectories at postnatal stages (Ehrman et al., 2013). The direct pathway defects observed at the level of the subthalamic nucleus and $\mathrm{SNr}$ in postnatal $D I X$-cre driven $I s I 1 \mathrm{cKO}$ appear similar to that observed in the Sema 3e mutants (Ehrman et al., 2013). However, the aberrant axonal innervation of the dorsal thalamus was not observed in Is $11 \mathrm{cKOs}$ at the postnatal time points examined. Using the Sox 8-EGFPBAC transgenic mice, we did observe abnormal dSPN innervation of the dorsal thalamus in DIX1-cre; IsI1 cKOs at birth, suggesting that these aberrantly projecting direct pathway axons are pruned back from the dorsal thalamus at postnatal times. These findings demonstrate the utility of the Sox 8 -EGFPBAC mice to study the development of basal ganglia circuitry in both wild type and genetic mutant backgrounds.

\section{ACKNOWLEDGEMENTS}

We thank M. Wegner for the Sox8 antibody as well as W.H. Klein and X. Mu for the Isl1 floxed mice and T. Jessell for the $I s 11^{\text {cre }}$ mice.

Support: This work was supported by NIH R01 MH090740 and NIH R01 NS044080 to K.C.

\section{Abbreviations used in the text and figures}

$\begin{array}{ll}\text { Ctx } & \text { Cortex } \\ \text { dSPN } & \text { Direct pathway striatal projection neuron } \\ \text { EP } & \text { Entopeduncular nucleus } \\ \text { GP } & \text { Globus pallidus } \\ \text { Hyp } & \text { Hypothalamus }\end{array}$




$\begin{array}{ll}\text { iSPN } & \text { Indirect pathway striatal projection neuron } \\ \text { LGE } & \text { Lateral ganglionic eminence } \\ \text { MGE } & \text { Medial ganglionic eminence } \\ \text { OPC } & \text { Oligodendrocyte precursor cell } \\ \text { SNc } & \text { Substantia nigra compacta } \\ \text { SNr } & \text { Substantia nigra reticulata } \\ \text { STN } & \text { Subthalamic nucleus } \\ \text { SVZ } & \text { Subventricular zone } \\ \text { rTh } & \text { Reticular thalamus } \\ \text { Th } & \text { Thalamus } \\ \text { VTA } & \text { Ventral tegmental area } \\ \text { VZ } & \text { Ventricular zone }\end{array}$

\section{LITERATURE CITED}

Albin RL. 1995 The pathophysiology of chorea/ballism and Parkinsonism. Parkinsonism Relat Disord 1(1):3-11. [PubMed: 18590996]

Albin RL, Tagle DA. 1995 Genetics and molecular biology of Huntington's disease. Trends Neurosci 18( 1): 11-14. [PubMed: 7535483]

Albin RL, Young AB, Penney JB. 1989 The functional anatomy of basal ganglia disorders. Trends Neurosci 12(10):366-375. [PubMed: 2479133]

Anderson SA, Qiu M, Bulfone A, Eisenstat DD, Meneses J, Pedersen R, Rubenstein JL. 1997 Mutations of the homeobox genes Dlx-1 and Dlx-2 disrupt the striatal subventricular zone and differentiation of late born striatal neurons. Neuron 19(1):27-37. [PubMed: 9247261]

Arlotta P, Molyneaux BJ, Jabaudon D, Yoshida Y, Macklis JD. 2008 Ctip2 controls the differentiation of medium spiny neurons and the establishment of the cellular architecture of the striatum. $\mathbf{J}$ Neurosci 28(3):622-632. [PubMed: 18199763]

Bacon C, Schneider M, Le Magueresse C, Froehlich H, Sticht C, Gluch C, Monyer H, Rappold GA. 2015 Brain-specific Foxp1 deletion impairs neuronal development and causes autistic-like behaviour. Mol Psychiatry 20(5):632-639. [PubMed: 25266127]

Casarosa S, Fode C, Guillemot F. 1999 Mash1 regulates neurogenesis in the ventral telencephalon. Development 126(3):525-534. [PubMed: 9876181]

Chang CW, Tsai CW, Wang HF, Tsai HC, Chen HY, Tsai TF, Takahashi H, Li HY, Fann MJ, Yang CW, Hayashizaki Y, Saito T, Liu FC. 2004 Identification of a developmentally regulated striatumenriched zinc-finger gene, Nolz-1, in the mammalian brain. Proc Natl Acad Sci U S A 101(8):26132618. [PubMed: 14983057]

Chauvet S, Cohen S, Yoshida Y, Fekrane L, Livet J, Gayet O, Segu L, Buhot MC, Jessell TM, Henderson CE, Mann F. 2007 Gating of Sema3E/PlexinD1 signaling by neuropilin-1 switches axonal repulsion to attraction during brain development. Neuron 56(5):807-822. [PubMed: 18054858]

Corbin JG, Gaiano N, Machold RP, Langston A, Fishell G. 2000 The Gsh2 homeodomain gene controls multiple aspects of telencephalic development. Development 127(23):5007-5020. [PubMed: 11060228] 
Ehrman LA, Mu X, Waclaw RR, Yoshida Y, Vorhees CV, Klein WH, Campbell K. 2013 The LIM homeobox gene Isl1 is required for the correct development of the striatonigral pathway in the mouse. Proc Natl Acad Sci U S A 110(42):E4026-4035. [PubMed: 24082127]

Ehrman LA, Nardini D, Ehrman S, Rizvi TA, Gulick J, Krenz M, Dasgupta B, Robbins J, Ratner N, Nakafuku M, Waclaw RR. 2014 The protein tyrosine phosphatase Shp2 is required for the generation of oligodendrocyte progenitor cells and myelination in the mouse telencephalon. $\mathbf{J}$ Neurosci 34(10):3767-3778. [PubMed: 24599474]

Erickson CS, Zaitoun I, Haberman KM, Gosain A, Druckenbrod NR, Epstein ML. 2012 Sacral neural crest-derived cells enter the aganglionic colon of Ednrb-/- mice along extrinsic nerve fibers. J Comp Neurol 520(3):620-632. [PubMed: 21858821]

Fishell G, van der Kooy D. 1987 Pattern formation in the striatum: developmental changes in the distribution of striatonigral neurons. J Neurosci 7(7): 1969-1978. [PubMed: 2886562]

Garel S, Marin F, Grosschedl R, Charnay P. 1999 Ebf1 controls early cell differentiation in the embryonic striatum. Development 126(23):5285-5294. [PubMed: 10556054]

Gerfen CR (2004). Chapter 18 Basal Ganglia. Paxinos, G. (2004) The rat nervous system (3rd ed.) Amsterdam; London : Elsevier/Academic Press.

Gerfen CR, Surmeier DJ. 2011 Modulation of striatal projection systems by dopamine. Annu Rev Neurosci 34:441-466. [PubMed: 21469956]

Gong S, Zheng C, Doughty ML, Losos K, Didkovsky N, Schambra UB, Nowak NJ, Joyner A, Leblanc G, Hatten ME, Heintz N. 2003 A gene expression atlas of the central nervous system based on bacterial artificial chromosomes. Nature 425(6961):917-925. [PubMed: 14586460]

Gonzales KK, Pare JF, Wichmann T, Smith Y. 2013 GABAergic inputs from direct and indirect striatal projection neurons onto cholinergic interneurons in the primate putamen. J Comp Neurol 521(11): 2502-2522. [PubMed: 23296794]

Kawaguchi Y 1993 Physiological, morphological, and histochemical characterization of three classes of interneurons in rat neostriatum. J Neurosci 13(11):4908-4923. [PubMed: 7693897]

Kellerer S, Schreiner S, Stolt CC, Scholz S, Bosl MR, Wegner M. 2006 Replacement of the Sox 10 transcription factor by Sox 8 reveals incomplete functional equivalence. Development 133(15): 2875-2886. [PubMed: 16790476]

Kemp JM, Powell TP. 1971 The structure of the caudate nucleus of the cat: light and electron microscopy. Philos Trans R Soc Lond B Biol Sci 262(845):383-401. [PubMed: 4107495]

Ko HA, Chen SY, Chen HY, Hao HJ, Liu FC. 2013 Cell type-selective expression of the zinc fingercontaining gene Nolz-1/Zfp503 in the developing mouse striatum. Neurosci Lett 548:44-49. [PubMed: 23684982]

Leisman G, Melillo R. 2013 The basal ganglia: motor and cognitive relationships in a clinical neurobehavioral context. Rev Neurosci 24(1):9-25. [PubMed: 23241666]

Lobo MK, Karsten SL, Gray M, Geschwind DH, Y ang XW. 2006 FACS-array profiling of striatal projection neuron subtypes in juvenile and adult mouse brains. Nat Neurosci 9(3):443-452. [PubMed: 16491081]

Lobo MK, Yeh C, Yang XW. 2008 Pivotal role of early B-cell factor 1 in development of striatonigral medium spiny neurons in the matrix compartment. J Neurosci Res 86(10):2134-2146. [PubMed: 18338816]

Long JE, Swan C, Liang WS, Cobos I, Potter GB, Rubenstein JL. 2009 Dlx1\&2 and Mashl transcription factors control striatal patterning and differentiation through parallel and overlapping pathways. J Comp Neurol 512(4):556-572. [PubMed: 19030180]

Lu KM, Evans SM, Hirano S, Liu FC. 2014 Dual role for Islet-1 in promoting striatonigral and repressing striatopallidal genetic programs to specify striatonigral cell identity. Proc Natl Acad Sci U S A 111(1):E168-177. [PubMed: 24351932]

Macpherson T, Morita M, Hikida T. 2014 Striatal direct and indirect pathways control decision-making behavior. Front Psychol 5:1301. [PubMed: 25429278]

Marin O, Anderson SA, Rubenstein JL. 2000 Origin and molecular specification of striatal interneurons. J Neurosci 20(16):6063-6076. [PubMed: 10934256]

Morello F, Prasad AA, Rehberg K, Vieira de Sa R, Anton-Bolanos N, Leyva-Diaz E, Adolfs Y, Tissir F, Lopez-Bendito G, Pasterkamp RJ. 2015 Frizzled3 Controls Axonal Polarity and Intermediate 
Target Entry during Striatal Pathway Development. J Neurosci 35(42):14205-14219. [PubMed: 26490861]

Mu X, Fu X, Beremand PD, Thomas TL, Klein WH. 2008 Gene regulation logic in retinal ganglion cell development: Isl1 defines a critical branch distinct from but overlapping with Pou4f2. Proc Natl Acad Sci U S A 105(19):6942-6947. [PubMed: 18460603]

Obeso JA, Rodriguez-Oroz MC, Stamelou M, Bhatia KP, Burn DJ. 2014 The expanding universe of disorders of the basal ganglia. Lancet 384(9942):523-531. [PubMed: 24954674]

Pei Z, Wang B, Chen G, Nagao M, Nakafuku M, Campbell K. 2011 Homeobox genes Gsx1 and Gsx2 differentially regulate telencephalic progenitor maturation. Proc Natl Acad Sci U S A 108(4): 1675-1680. [PubMed: 21205889]

Qin S, Madhavan M, Waclaw RR, Nakafuku M, Campbell K. 2016 Characterization of a new Gsx2-cre line in the developing mouse telencephalon. Genesis 54(10):542-549. [PubMed: 27618396]

Shuen JA, Chen M, Gloss B, Calakos N. 2008 Drd1a-tdTomato BAC transgenic mice for simultaneous visualization of medium spiny neurons in the direct and indirect pathways of the basal ganglia. $\mathrm{J}$ Neurosci 28(11):2681-2685. [PubMed: 18337395]

Sock E, Schmidt K, Hermanns-Borgmeyer I, Bosl MR, Wegner M. 2001 Idiopathic weight reduction in mice deficient in the high-mobility-group transcription factor Sox8. Mol Cell Biol 21(20):69516959. [PubMed: 11564878]

Srinivas S, Watanabe T, Lin CS, William CM, Tanabe Y, Jessell TM, Costantini F. 2001 Cre reporter strains produced by targeted insertion of EYFP and ECFP into the ROSA26 locus. BMC Dev Biol 1:4. [PubMed: 11299042]

Stolt CC, Lommes P, Sock E, Chaboisser M-C, Schedl A, Wegner M. 2002 Terminal differentiation of myelin-forming oligodendrocytes depends on the transcription factor Sox10. Genes Dev 16:165170. [PubMed: 11799060]

Stolt CC, Lommes P, Sock E, Chaboisser M-C, Schedl A, Wegner M. 2003 The Sox9 transcription factor determines glial fate choice in the developing spinal cord. Genes Dev 17:1677-1689. [PubMed: 12842915]

Stolt CC, Lommes P, Friedrich RP, Wegner M. 2004 Transcription factors Sox8 and Sox10 perform non-equivalent roles during oligodendrocyte development despite functional redundancy. Development 131(10):2349-2358. [PubMed: 15102707]

Stolt CC, Schmitt S, Lommes P, Sock E, Wegner M. 2005 Impact of transcription factor Sox 8 on oligodendrocyte specification in the mouse embryonic spinal cord. Dev Biol 281(2):309-317. [PubMed: 15893981]

Tamura S, Morikawa Y, Iwanishi H, Hisaoka T, Senba E. 2004 Foxp1 gene expression in projection neurons of the mouse striatum. Neuroscience 124(2):261-267. [PubMed: 14980377]

Toresson H, Campbell K. 2001 A role for Gsh1 in the developing striatum and olfactory bulb of Gsh2 mutant mice. Development 128(23):4769-4780. [PubMed: 11731457]

Toresson H, Mata de Urquiza A, Fagerstrom C, Perlmann T, Campbell K. 1999 Retinoids are produced by glia in the lateral ganglionic eminence and regulate striatal neuron differentiation. Development 126(6):1317-1326. [PubMed: 10021349]

Toresson H, Potter SS, Campbell K. 2000 Genetic control of dorsal-ventral identity in the telencephalon: opposing roles for Pax6 and Gsh2. Development 127(20):4361-4371. [PubMed: 11003836]

Waclaw RR, Wang B, Pei Z, Ehrman LA, Campbell K. 2009 Distinct temporal requirements for the homeobox gene Gsx2 in specifying striatal and olfactory bulb neuronal fates. Neuron 63(4):451465. [PubMed: 19709628]

Wang B, Long JE, Flandin P, Pla R, Waclaw RR, Campbell K, Rubenstein JL. 2013 Loss of Gsx1 and Gsx2 function rescues distinct phenotypes in Dlx1/2 mutants. J Comp Neurol 521(7): 1561-1584. [PubMed: 23042297]

Wang B, Lufkin T, Rubenstein JL. 2011 Dlx6 regulates molecular properties of the striatum and central nucleus of the amygdala. J Comp Neurol 519(12):2320-2334. [PubMed: 21452241]

Wang B, Waclaw RR, Allen ZJ, 2nd, Guillemot F, Campbell K 2009 Ascl1 is a required downstream effector of Gsx gene function in the embryonic mouse telencephalon. Neural Dev 4:5. [PubMed: 19208224] 
Wang Z, Kai L, Day M, Ronesi J, Yin HH, Ding J, Tkatch T, Lovinger DM, Surmeier DJ. 2006 Dopaminergic control of corticostriatal long-term synaptic depression in medium spiny neurons is mediated by cholinergic interneurons. Neuron 50(3):443-452. [PubMed: 16675398]

Workman AD, Charvet CJ, Clancy B, Darlington RB, Finlay BL. 2013 Modeling transformations of neurodevelopmental sequences across mammalian species. J Neurosci 33(17):7368-7383. [PubMed: 23616543]

Xu Q, Tam M, Anderson SA. 2008 Fate mapping Nkx2.1-lineage cells in the mouse telencephalon. J Comp Neurol 506(1):16-29. [PubMed: 17990269]

Yun K, Fischman S, Johnson J, Hrabe de Angelis M, Weinmaster G, Rubenstein JL. 2002 Modulation of the notch signaling by Mash 1 and Dlx $1 / 2$ regulates sequential specification and differentiation of progenitor cell types in the subcortical telencephalon. Development 129(21):5029-5040. [PubMed: 12397111]

Yun K, Garel S, Fischman S, Rubenstein JL. 2003 Patterning of the lateral ganglionic eminence by the Gsh1 and Gsh2 homeobox genes regulates striatal and olfactory bulb histogenesis and the growth of axons through the basal ganglia. J Comp Neurol 461(2):151-165. [PubMed: 12724834]

Yun K, Potter S, Rubenstein JL. 2001 Gsh2 and Pax6 play complementary roles in dorsoventral patterning of the mammalian telencephalon. Development 128(2): 193-205. [PubMed: 11124115]

Zhang Q, Zhang Y, Wang C, Xu Z, Liang Q, An L, Li J, Liu Z, You Y, He M, Mao Y, Chen B, Xiong ZQ, Rubenstein JL, Yang Z. 2016 The Zinc Finger Transcription Factor Sp9 Is Required for the Development of Striatopallidal Projection Neurons. Cell Rep 16(5):1431-1444. [PubMed: 27452460] 


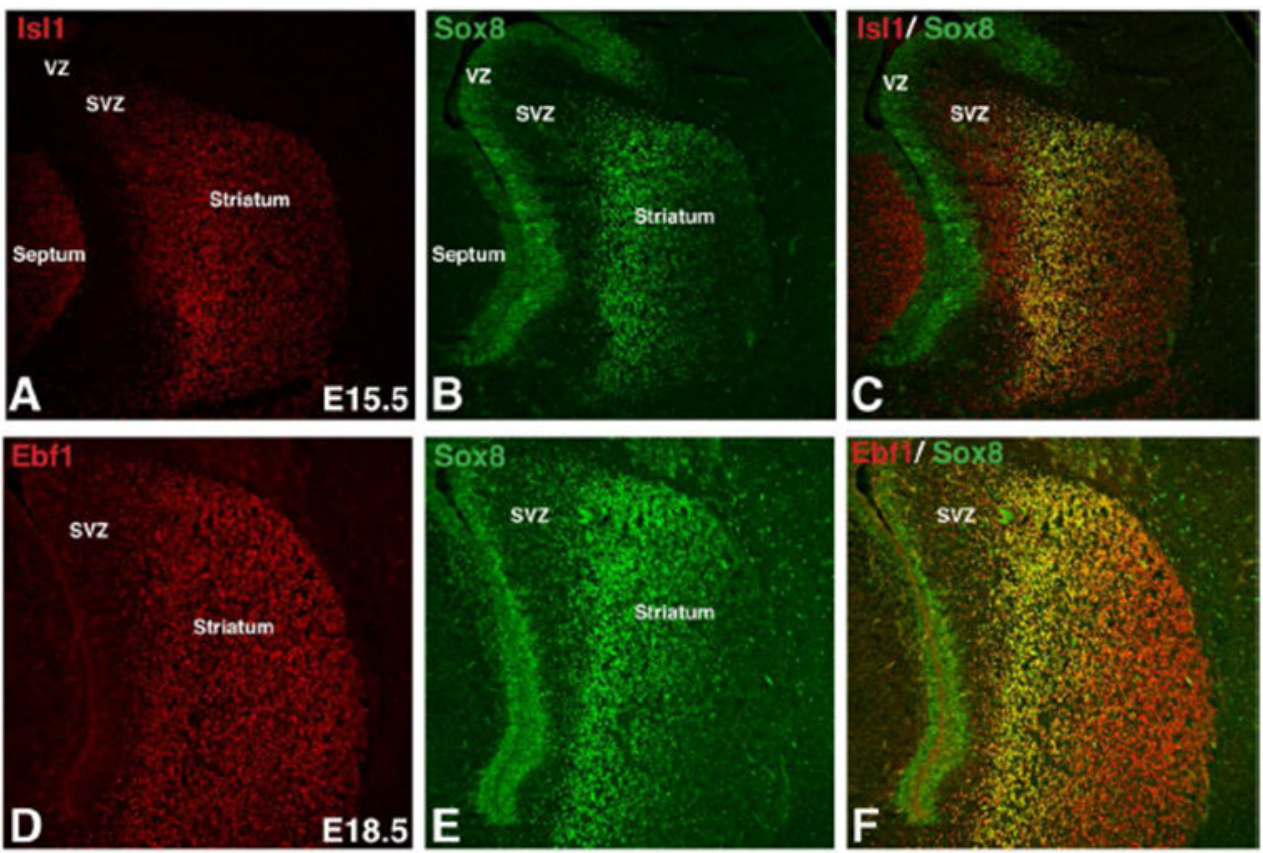
Is/1 ${ }^{\text {cre/+ }} ;$ RosaCAG-tdTomato/+
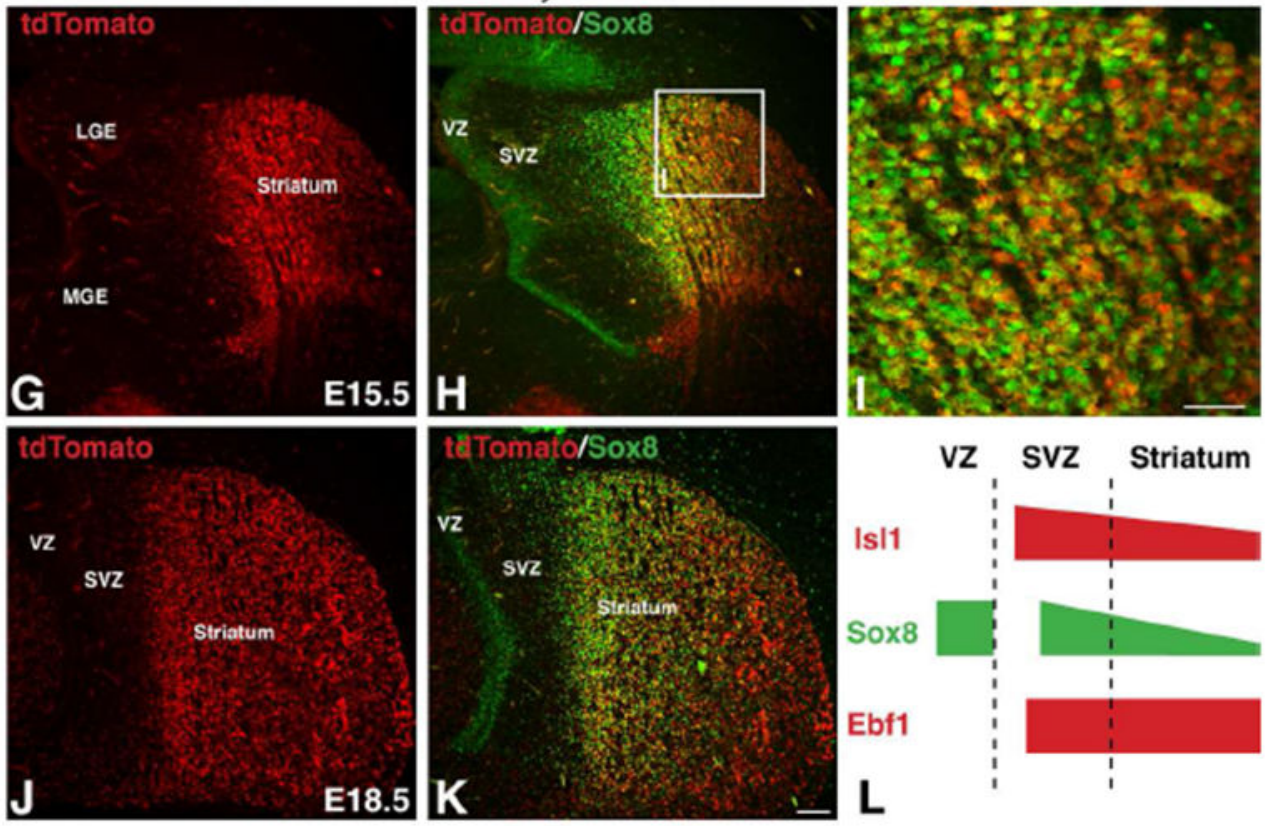

Figure 1.

(A-C) Confocal fluorescent images of coronal hemisections of E15.5 mouse brains immunostained for Is11 (A) and Sox8 (B) illustrate the basal ganglia distribution of both proteins. Sox 8 and Isl1 are co-expressed in the deep portions of the SVZ and in a decreasing gradient from medial to lateral within the striatum (C). (D-F) Sox8 (D) and Ebf1 (E) are coexpressed in the deep portions of the SVZ as well as in the medial region of the striatum at E18.5. Note, Ebf1 shows a rather uniform expression throughout the striatum $(\mathbf{F}) .(\mathbf{G}-\mathbf{K})$ Is 11 fate mapped striatal cells (tdTomoato ${ }^{+}$) showing co-localization of Sox8 at E15.5 (G-I) 
and E18.5 (J,K). (I) High power image of boxed area in $\mathbf{H}$ showing extensive colocalization Sox 8 and tdTomato in newborn SPNs. (L) Schematic illustration of the expression of Sox 8 in relation to the dSPN markers Isl1 and Ebf1 in the developing LGE showing the different gradients of expression in the SVZ and striatum as well as VZ.

Abbreviations: VZ: ventricular zone; SVZ: subventricular zone; MGE: medial ganglionic eminence; LGE: lateral ganglionic eminence. Scale bar: A-H, J, K $=100 \mu \mathrm{m} ; \mathrm{I}=30 \mu \mathrm{m}$. 


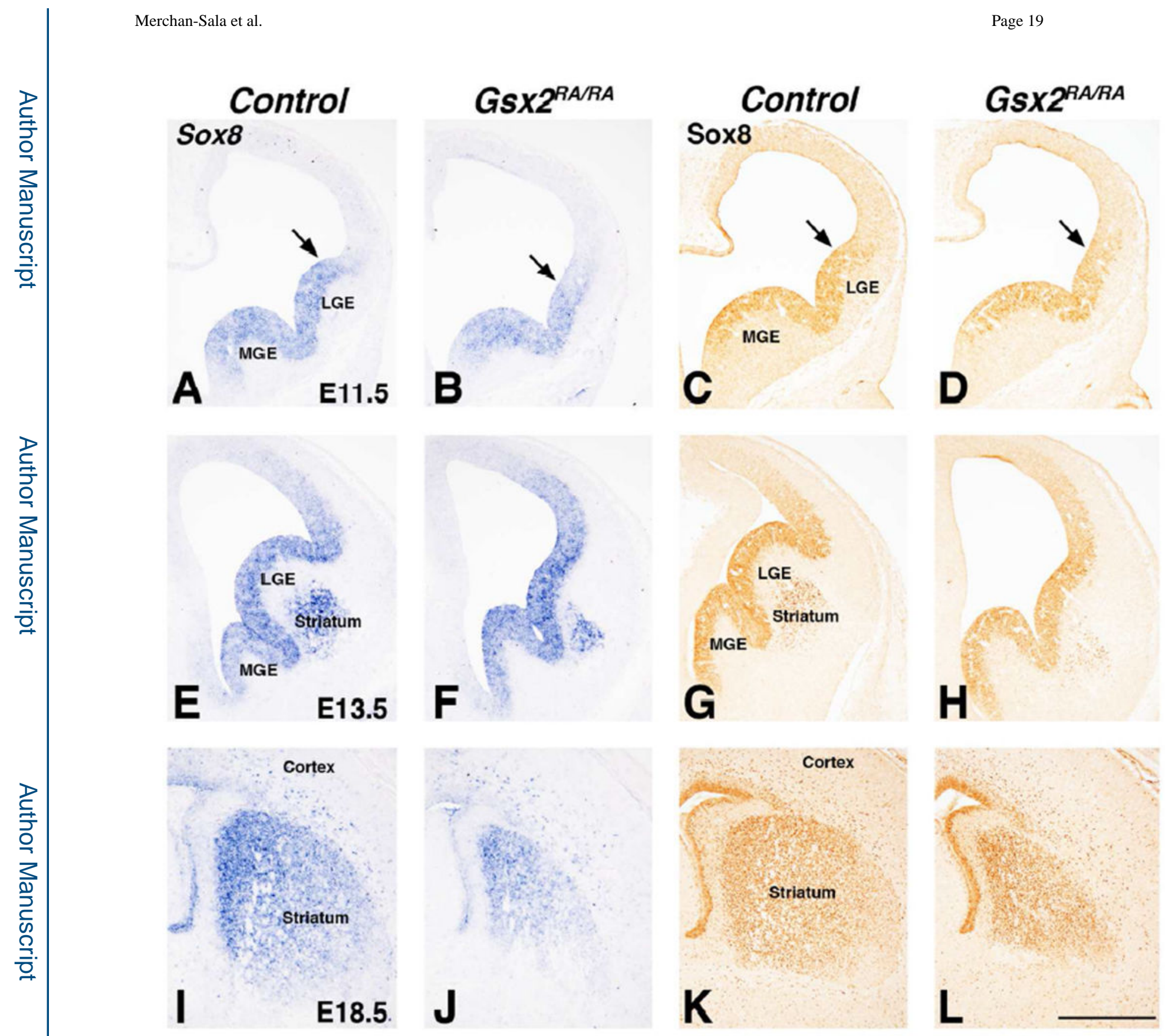

Figure 2.

Comparison of $\operatorname{Sox} 8$ gene and protein expression in control and Gs 2 mutants during striatal development. Mouse brain coronal hemisections in situ stained for $\operatorname{Sox} 8$ (A-B, E-F, I-J) and immunostained for Sox 8 (C-D, G-H, K-L). Sox 8 gene and protein expression is restricted to the ventricular zone (VZ) of the MGE and LGE at E11.5 (A,C). The Sox8 expression domain is shifted ventrally (compare arrows in $\mathbf{B}, \mathbf{D}$ with $\mathbf{A , C}$ ) in the VZ of the LGE in Gsx 2 mutants $(\mathbf{B}, \mathbf{D})$ as compared to controls $\left(G s X 2^{R A /+}\right)(\mathbf{A}, \mathbf{C})$. By E13.5, Sox8 gene and protein expression expands dorsally in the $\mathrm{VZ}$ and is also detected in the developing striatum (E, G). At this stage, GsX2 mutants $(\mathbf{F}, \mathbf{H})$ show no difference in the VZ expression of Sox 8, but display a clear reduction in the forming striatum (compare $\mathbf{F , H}$ to $\mathbf{E , G}$ ). At E18.5, Sox8 
remains robustly expressed in the striatum $(\mathbf{I}, \mathbf{K})$ and is reduced in $G s \times 2$ mutants $(\mathbf{J}, \mathbf{L})$.

Abbreviations: MGE: medial ganglionic eminence; LGE: lateral ganglionic eminence. Scale bar $=500 \mu \mathrm{m}$. 

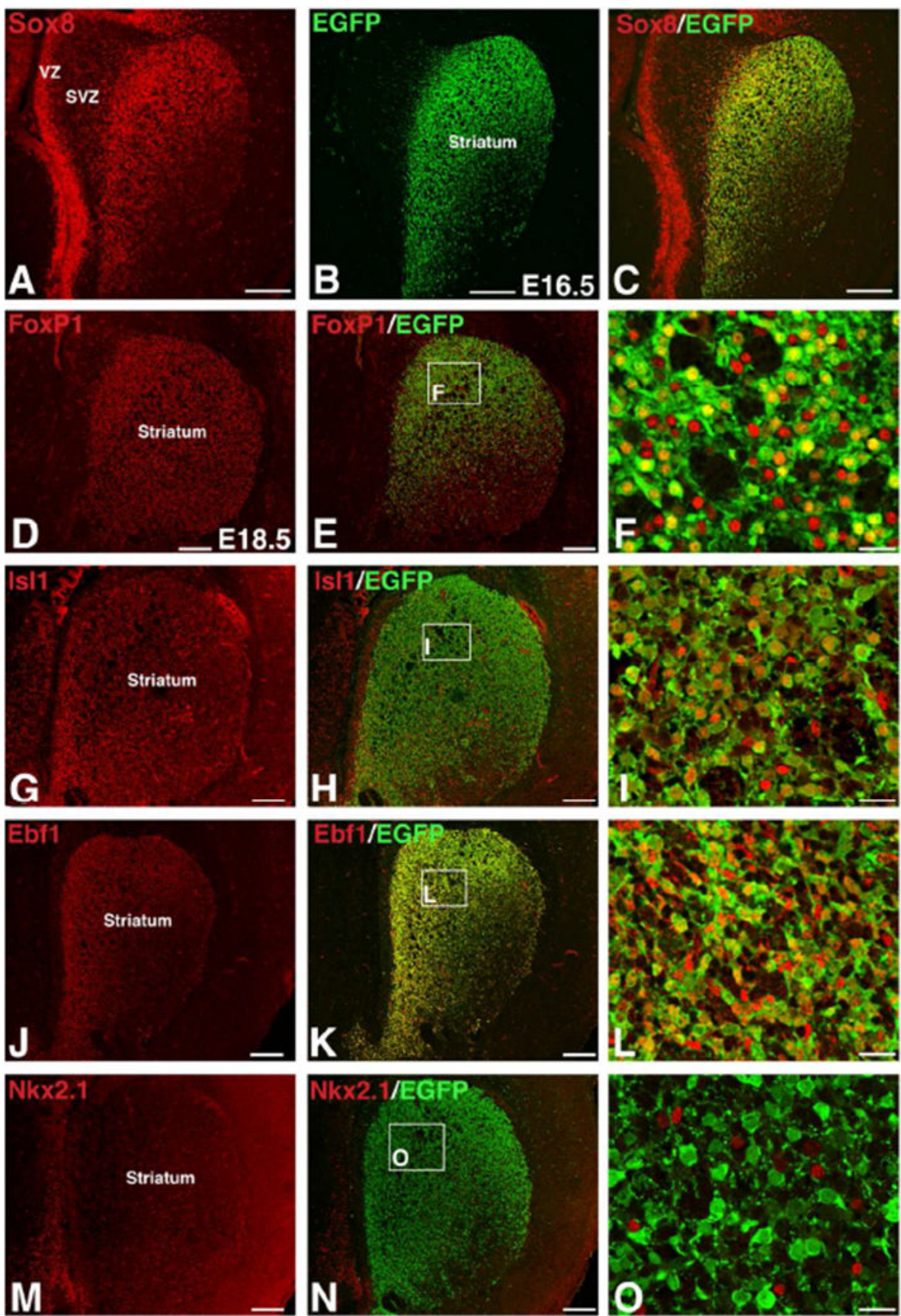

Figure 3.

(A-C) Coronal hemisections from E16.5 Sox8-EGFPBAC transgenic mouse brain stained for Sox8 (A) and EGFP (B), respectively. (C) Merged image showing EGFP recapitulates the expression of Sox 8 within the subventricualr zone (SVZ) and striatum but not in the ventricular zone (VZ). (D-O) Confocal pictures of E18.5 Sox8-EGFP coronal hemisections double stained for EGFP (green) and: FoxP1 (D-F), Is11 (G-I), Ebf1 (J-L) and Nkx2.1 (M$\mathbf{O})$ in red. (F,I,L,O) High power images of the respective boxed areas in the center column panels from E,H,K and N. As expected, FoxP1/EGFP staining reveals that $\mathrm{EGFP}^{+}$cells 
coexpress FoxP1 (E-F). Moreover, extensive co-labelling with the dSPN markers markers Is11 (H-I) and Ebf1 (K-L) is also observed. No colocalization was found with the interneuron marker Nkx2.1 (N-O). Abbreviations: VZ: ventricular zone; SVZ:

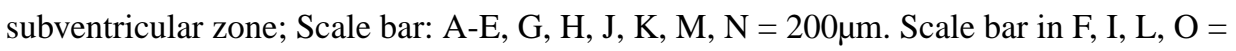
$20 \mu \mathrm{m}$. 

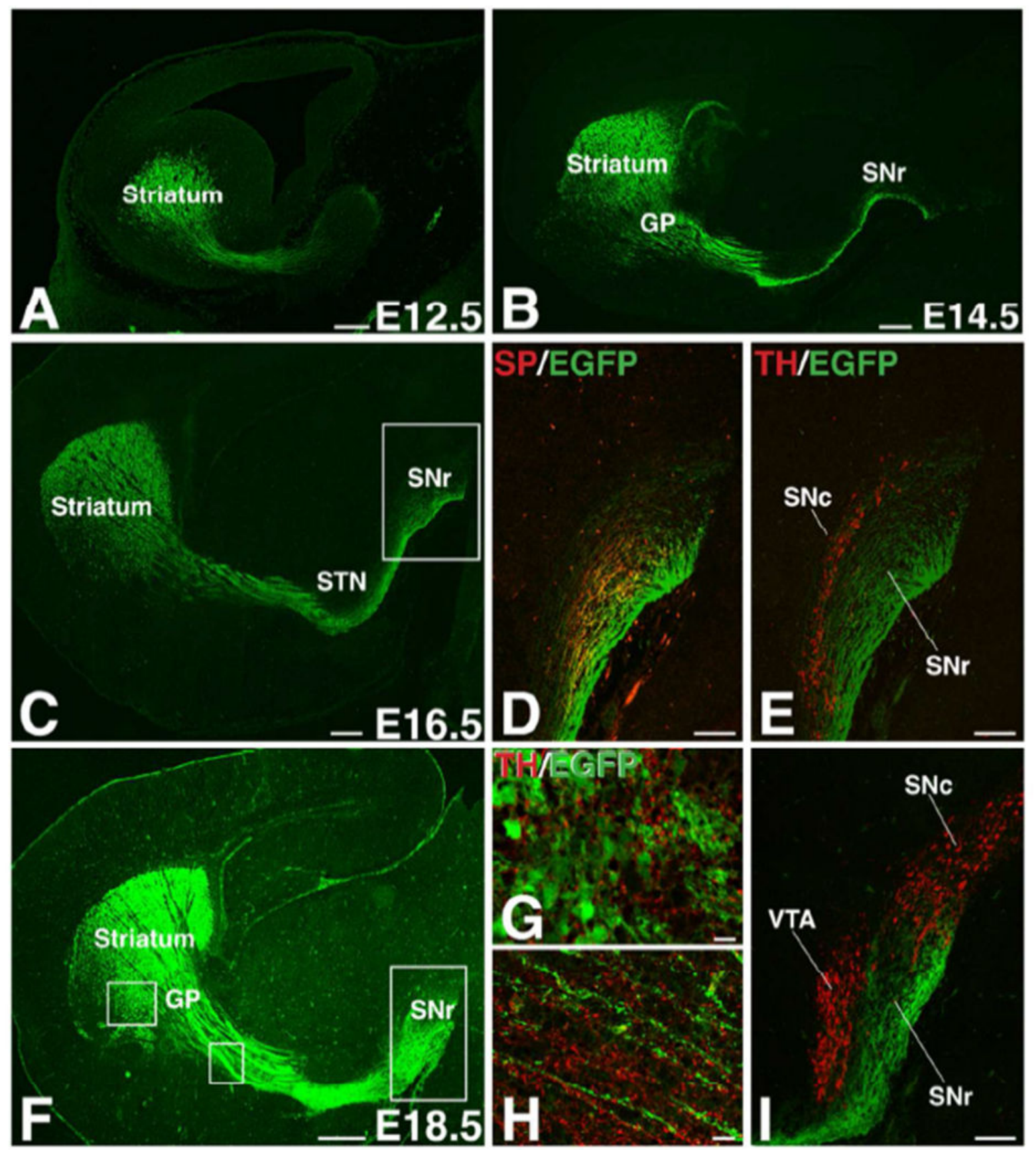

Figure 4.

$(\mathbf{A}, \mathbf{B}, \mathbf{C}, \mathbf{F})$ Low power images of sagittal sections of Sox 8-EGFP brains from E12.5 to E18.5. (A) At E12.5, EGFP fluorescence is found in dSPNs as well as in their axons which, at this stage, only reach the telencephalon/diencephalon boundary. (B) By E14.5, EGFP+ fibers are observed to reach the midbrain with the first terminals invading the SNr. (C) At E16.5, the internal capsule is well formed and many axons show a sterotypic trajectory on their way to the SNr. (D-E) High power confocal images of sagittal sections at the SNr level represented by the boxed area in C. (D) Double immunostaining with substance P, shows 
colocalization with the dSPN marker in $\mathrm{EGFP}^{+}$terminals of the developing $\mathrm{SNr}$. (E) TH neurons of the VTA and SNc can be observed dorsal to the EGFP terminals arborizing within the SNr at E16.5. (F) Low power sagittal view of the E18.5 Sox8-EGFP brain, showing a fully formed direct pathway. $(\mathbf{G}, \mathbf{H}, \mathbf{I})$ High power confocal images from representative areas boxed in $\mathbf{F}$. (G) $\mathrm{EGFP}^{+}$striatal neurons (i.e. dSPNs) are surrounded by $\mathrm{TH}^{+}$terminals. (H) Close association between descending $\mathrm{EGFP}^{+}$(i.e. direct pathway) and ascending $\mathrm{TH}^{+}$(i.e. dopaminergic) fibers is observed along the direct pathway trajectory. (I) Typical organization of the substantia nigra with a $\mathrm{TH}^{+} \mathrm{SNc} / \mathrm{VTA}$ dorsal and lateral to the $\mathrm{SNr}$ containing $\mathrm{EGFP}^{+}$terminals. Abbreviations: GP: globus pallidus; SNr: substantia nigra reticulata; SNc: substantia nigra pars compacta; STN: subthalamic nucleus; SP; substance P; TH; tyrosine hydroxylase; VTA: ventral tegmental area. Scale bar: in A-C $=200 \mu \mathrm{m}, \mathrm{G}-\mathrm{H}=$ $10 \mu \mathrm{m}$. D-E, $\mathrm{I}=100 \mu \mathrm{m} F=500 \mu \mathrm{m}$ 
Drd1-EGFP

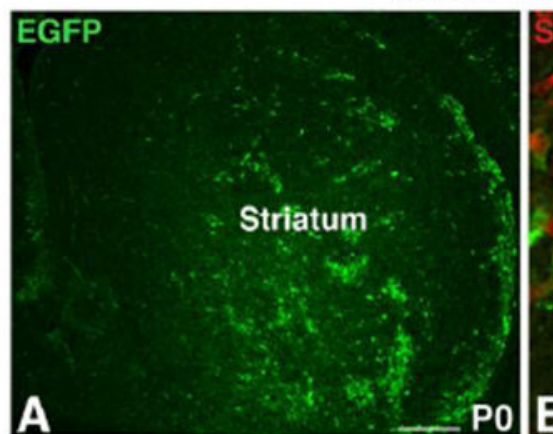



\section{Drd1-ta}

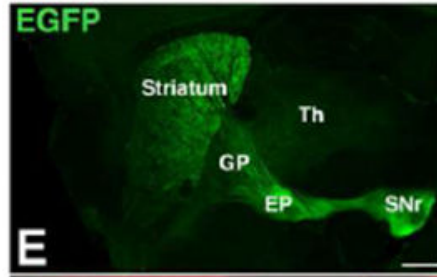

IdTomato

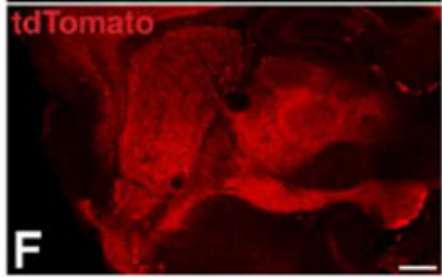

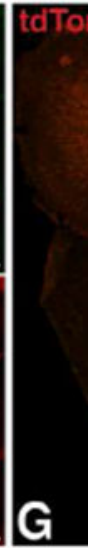

Drd2-EGFP

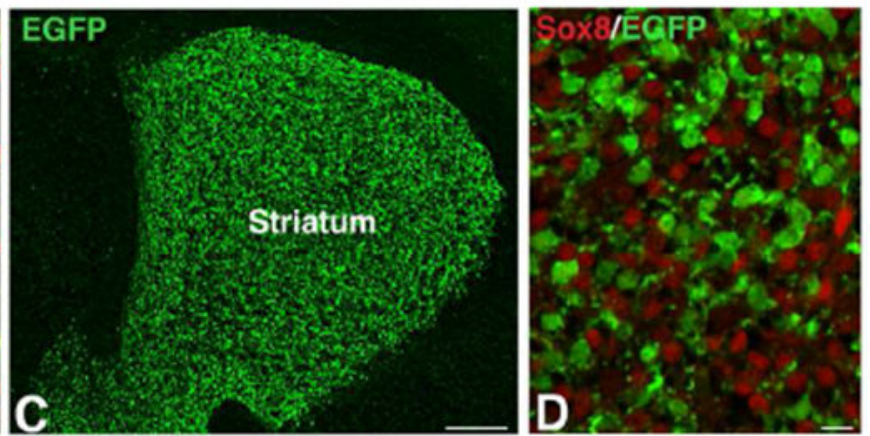

C.

8-EGFP

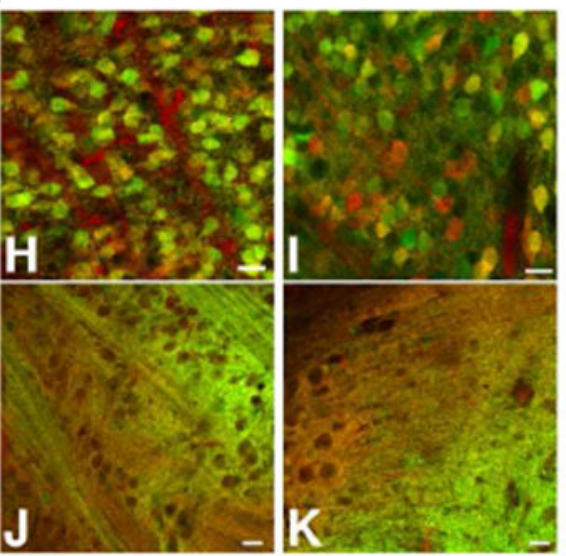

Figure 5.

(A) Coronal hemisection of Drd1-EGFP brain showing scattered patch-like EGFP expression in the P0 striatum. (B) High power confocal image of Sox8/EGFP double staining demonstrating that at $\mathrm{P} 0, \operatorname{Sox} 8^{+}$cells are more numerous than $\mathrm{EGFP}^{+}$cells, however, most colocalize with the EGFP ${ }^{+}$SPNs. (C) Coronal section of a Drd2-EGFP brain showing homogeneous distribution of $\mathrm{EGFP}^{+}$cells (i.e. iSPNs) throughout the striatal complex. (D) High power image showing a lack of co-labeling between EGFP and Sox8 indicating that iSPNs do not express Sox8. (E-G) Sagittal section from a P7 Drd1-tdTomato; Sox8-EGFP double transgenic brain show a high degree of overlap reporter expression pattern in the direct pathway. Sox 8 -EGFP appears to be more highly expressed in the dorsal versus ventral striatal complex. (H,I,J,K) High power confocal images from representative boxed areas along the direct pathway in $\mathbf{G}$. A more extensive colocalization between tdTomato and EGFP in the dorsal striatum dSPNs $(\mathbf{H})$ was observed as compared to those in the ventral region $(\mathbf{I})$. $(\mathbf{J}, \mathbf{K}) \mathrm{EGFP}^{+}$fibers and terminals co-label with tdTomato in the EP (J) and $\mathrm{SNr}(\mathbf{K})$ both of which represent targets of the direct pathway. Abbreviations: EP; entopeduncular nucleus; GP: globus pallidus; SNr: substantia nigra pars reticulata; Th: thalamus. Scale bar: in A, C $=200 \mu \mathrm{m} ; \mathrm{B}, \mathrm{D}=10 \mu \mathrm{m} ; \mathrm{E}-\mathrm{G}=500 \mu \mathrm{m} ; \mathrm{H}-\mathrm{K}=20 \mu \mathrm{m}$ 

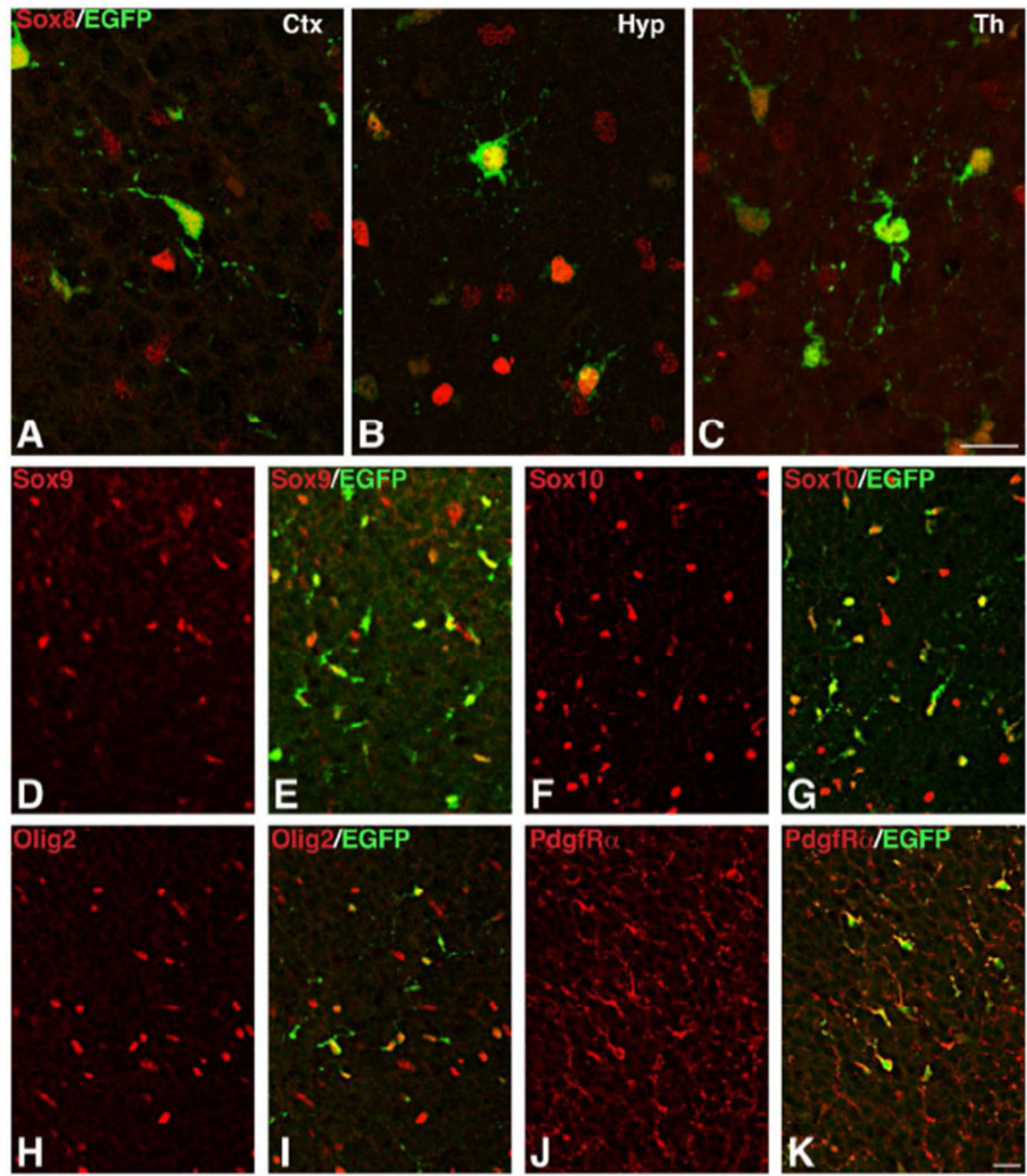

Figure 6.

$(\mathbf{A}, \mathbf{B}, \mathbf{C})$ High power confocal images of Sox 8-EGFP brains showing $\mathrm{EGFP}^{+}$cells in the cerebral cortex (A), hypothalamus (B) and thalamus (C) with oligodendrocyte progenitor cells (OPC) morphology and double stained with Sox8. (D-K) Double staining Sox8-EGFP sections with Sox9 (D,E), Sox10 (F,G), Olig2 (H,I) or PDGFRa (J,K) shows that the vast majority of $\mathrm{EGFP}^{+}$cells in the cerebral cortex express typical OPC markers. Abbreviations: Ctx: cerebral cortex; Hyp: hypothalamus; Th: thalamus. Scale bar: A-K $=20 \mu \mathrm{m}$ 
Control
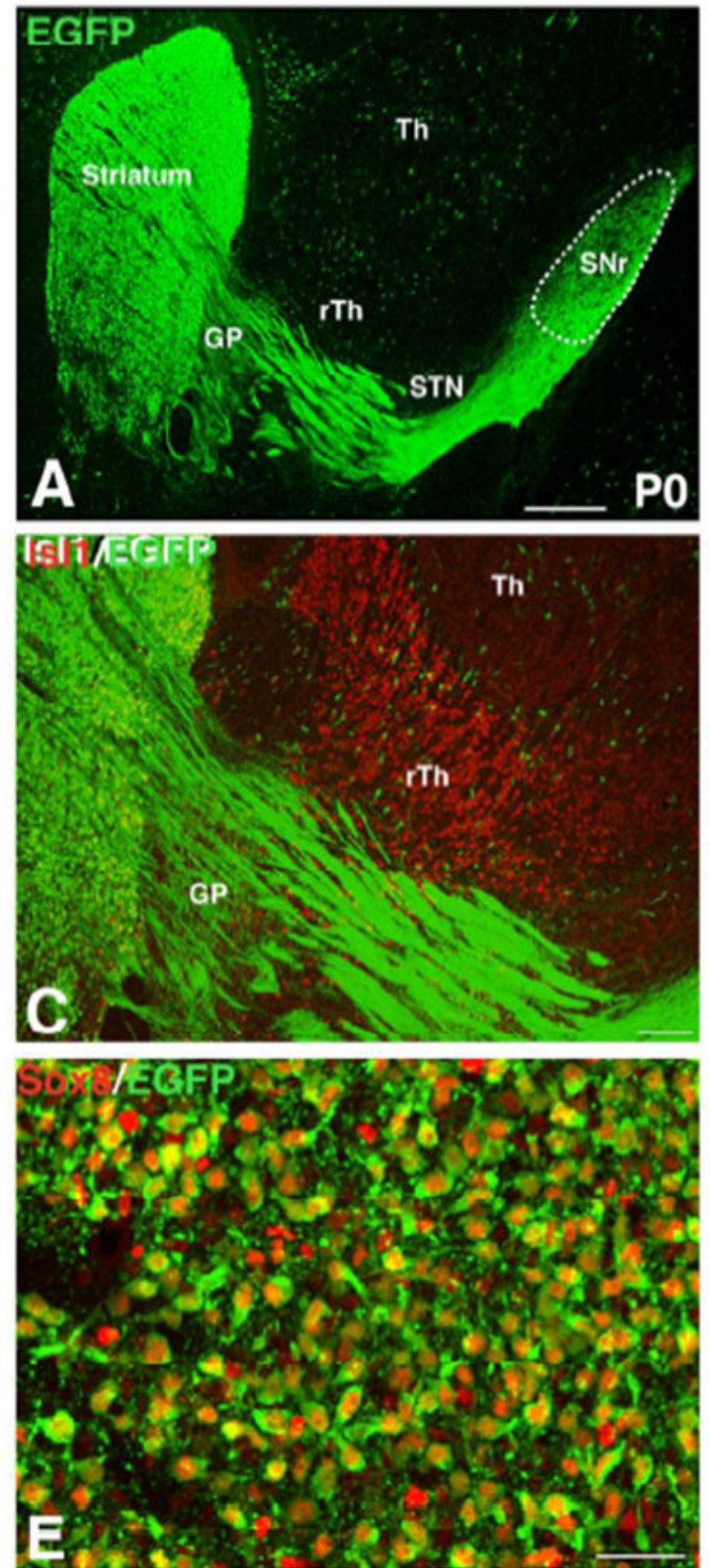

DIX1-cre; Is/ $1^{1 t / 1} ;$ Sox8-EGFP
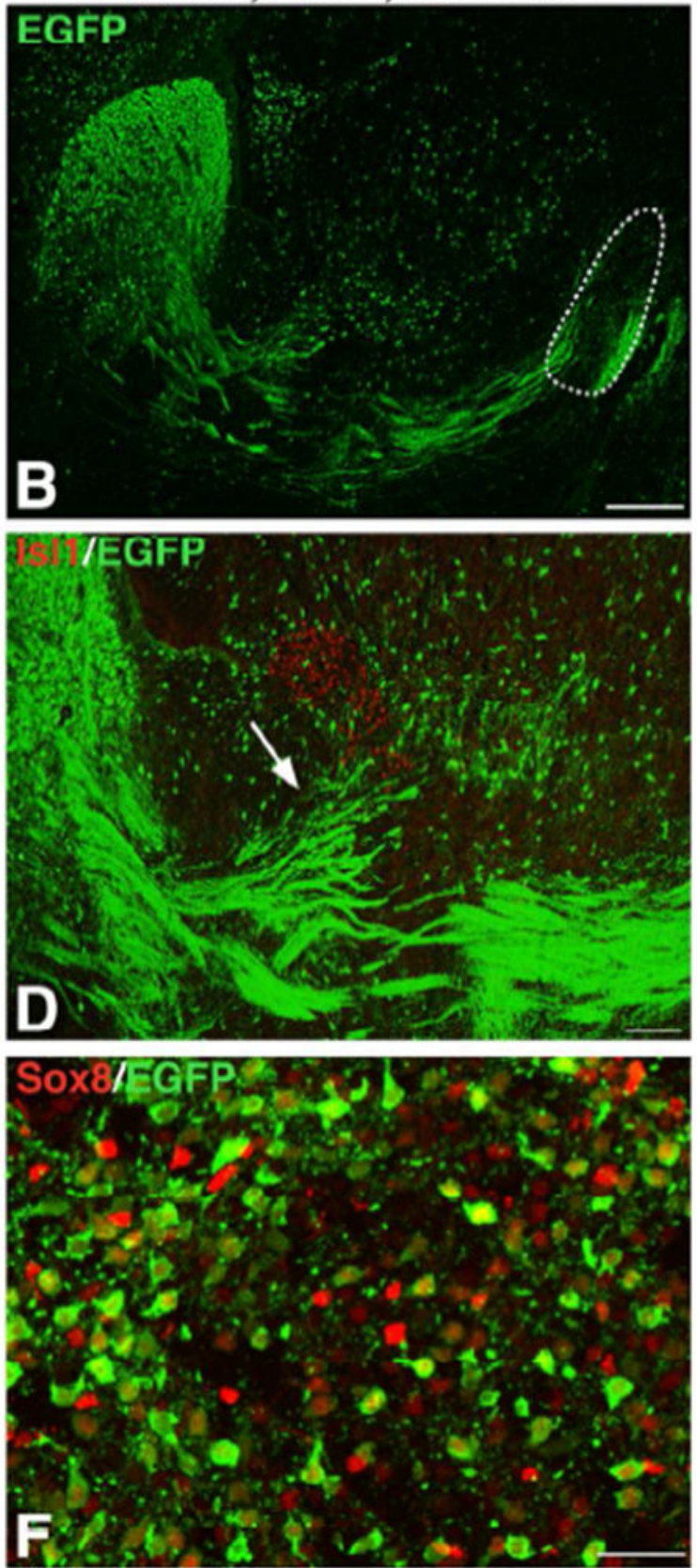

Figure 7.

Sagittal views of control (IsI1 ${ }^{f l /+}$; Sox 8 -EGFP) (A,C,E,G) and $I s 11 \mathrm{cKO}(\mathbf{B}, \mathbf{D}, \mathbf{F}, \mathbf{H})$ brains showing the direct pathway as marked by EGFP. The loss of Is11 results in a serve reduction of $\mathrm{EGFP}^{+}$cells within the striatum as well as $\mathrm{EGFP}^{+}$fibers in the direct pathway (B), as compared to control (A). (C,D) Higher power confocal images of $\mathbf{A}$ and $\mathbf{B}$ double stained for Isl1 and EGFP show the extent of Isl1 deletion in the conditional mutant (D). Note that the reduced Isl1 expression (red) in the reticular thalamic nucleus (rTh) corresponds with the misdirection of EGFP axons towards the thalamus (arrow in D) as compared to that seen in 
the control (C). Double staining for EGFP and Sox8 in the Is $11 \mathrm{cKO}$ striatum (F) shows a severe reduction in positive cells (in line with the reported cell death phenotype), as compared to the control (E). Abbreviations: rTh: reticular thalamus; SNr: substantia nigra pars reticulate; STN: subthalamic nucleus; Th: thalamus. Scale bar: A, B = 300 $\mu \mathrm{m} ; \mathrm{C}, \mathrm{D}=$ $100 \mu \mathrm{m} ; \mathrm{E}, \mathrm{F}=20 \mu \mathrm{m}$. 
Table 1.

Antibodies used for immunohistochemistry

\begin{tabular}{|c|c|c|c|}
\hline Antigen & Description of immunogen & Host species, Source, catalog No., RRID & Dilution \\
\hline Isl1 & E. coli-derived recombinant human Islet-1Met4-Ala349 & $\begin{array}{l}\text { Goat polyclonal, R and D Systems Cat\# AF1837, } \\
\text { RRID:AB_2126324 }\end{array}$ & $1: 500$ \\
\hline Sox 8 & $\begin{array}{c}\text { Purified bacterially expressed protein consisting of amino } \\
\text { acids } 2-60 \text { of mouse Sox } 8 \text { fused to glutathione-S- } \\
\text { transferase }\end{array}$ & $\begin{array}{l}\text { Guinea pig polyclonal, Dr. Michael Wegner , RRID: } \\
\qquad \text { AB_2571872 }\end{array}$ & $1: 500$ \\
\hline GFP & Recombinant GFP protein & $\begin{array}{c}\text { Chicken polyclonal, Aves Labs Cat\# GFP-1020, } \\
\text { RRID:AB_10000240 }\end{array}$ & $1: 1000$ \\
\hline Ebf1 & $\begin{array}{l}\text { KLH-conjugated linear peptide corresponding to mouse } \\
\text { EBF-1 }\end{array}$ & $\begin{array}{l}\text { Rabbit polyclonal, Millipore Cat\# AB10523, RRID: } \\
2636856\end{array}$ & $1: 1000$ \\
\hline FoxP1 & $\begin{array}{l}\text { Synthetic peptide derived from human FoxP1 within } \\
\text { residues } 650 \text { to the C-terminus }\end{array}$ & $\begin{array}{c}\text { Rabbit polyclonal, Abcam Cat\# ab57216, } \\
\text { RRID:AB_941648 }\end{array}$ & $1: 4000$ \\
\hline $\mathrm{Nkx} 2.1$ & Recombinant rat TTF-1 6his fusion & $\begin{array}{l}\text { Rabbit polyclonal, Seven Hills Bioreagents Cat\# } \\
\text { WRAB-1231, RRID:AB_451727 }\end{array}$ & $1: 500$ \\
\hline $\mathrm{TH}$ & $\begin{array}{l}\text { Synthetic peptides from human and mouse TH gene } \\
\text { product (P07101 and P24529) }\end{array}$ & $\begin{array}{c}\text { Chicken polyclonal, Aves Labs Cat\# TYH, } \\
\text { RRID:AB_10013440 }\end{array}$ & $1: 1000$ \\
\hline SubsP & Substance $\mathrm{P}$ conjugated to BSA & $\begin{array}{l}\text { Rat monoclonal, Millipore Cat\# MAB356, } \\
\text { RRID:AB_94639 }\end{array}$ & $1: 500$ \\
\hline Sox 9 & Amino acids $407-496$ of Sox- 9 of human origin & $\begin{array}{l}\text { Rabbit polyclonal, Santa Cruz Biotechnology Cat\# } \\
\text { sc-20095, RRID:AB_661282 }\end{array}$ & $1: 2000$ \\
\hline Sox 10 & Human Sox 10 N-terminus & $\begin{array}{l}\text { Goat polyclonal, Santa Cruz Biotechnology Cat\# } \\
\text { sc-17342, RRID:AB_2195374 }\end{array}$ & $1: 500$ \\
\hline Olig2 & Recombinant mouse Olig2 & $\begin{array}{l}\text { Rabbit polyclonal, Millipore Cat\# AB9610, } \\
\text { RRID:AB_570666 }\end{array}$ & $1: 2000$ \\
\hline PDGFRa & Human PDGFRa C-terminus & $\begin{array}{c}\text { Rabbit polyclonal, Santa Cruz Biotechnology Cat\# } \\
\text { sc-338, RRID:AB_631064 }\end{array}$ & $1: 200$ \\
\hline Tomato & $\begin{array}{l}\text { DsRed-Express, Discosoma sp. Variant of red fluorescent } \\
\text { protein }\end{array}$ & $\begin{array}{l}\text { Rabbit polyclonal, Clontech Laboratories, Inc. Cat\# } \\
\text { 632496, RRID:AB_10015246 }\end{array}$ & $1: 1000$ \\
\hline
\end{tabular}

